\title{
Surface Reaction of ZnO Nanowires with Electron-Beam Generated Alumina Vapor
}

\author{
Hong Jin Fan, ${ }^{*},,+$ Andriy Lotnyk,${ }^{\dagger}$ Roland Scholz, ${ }^{\dagger}$ Yang Yang, ${ }^{\dagger}$ Dong Sik Kim, ${ }^{\dagger}$ \\ Eckhard Pippel, ${ }^{\dagger}$ Stephan Senz, ${ }^{\dagger}$ Dietrich Hesse, ${ }^{\dagger}$ and Margit Zacharias ${ }^{\dagger, \#}$ \\ Max Planck Institute of Microstructure Physics, Weinberg 2, 06120 Halle, Germany, Department of Earth \\ Sciences, University of Cambridge, Cambridge CB2 3EQ, United Kingdom, Faculty of Applied Science \\ (IMTEK), Albert-Ludwigs-University Freiburg, Georges-Köhler-Allee, 79110 Freiburg, Germany
}

Received: December 28, 2007; In Final Form: February 22, 2008

\begin{abstract}
Single-crystal $\mathrm{ZnO}$ nanowires are reacted at $800-900{ }^{\circ} \mathrm{C}$ in vacuum with alumina vapor generated by electron beam evaporation. The morphology changes after the solid-vapor reactions are studied in detail using electron microscopy and compared to other similar spinel nanostructures. Unlike other solid-vapor reactions like $\mathrm{MgO}-\mathrm{Al}_{2} \mathrm{O}_{3}$ and $\mathrm{ZnO}-\mathrm{Ga}_{2} \mathrm{O}_{3}$ where a continuous spinel layer is formed, the reaction of $\mathrm{ZnO}$ nanowires with alumina vapor is unique. The initially smooth surfaces of $\mathrm{ZnO}$ nanowires become rugged due to surface decomposition without the growth of spinel layers. A formation mechanism is proposed that the surface reaction of $\mathrm{ZnO}$ with alumina vapor might constitute a process of a unilateral transport of $\mathrm{ZnO}$ and the associated surface diffusion.
\end{abstract}

\section{Introduction}

The controlled fabrication and assembly has been the mainstream of the nanowire research driven by their application potential as building blocks for semiconductor electronic and optoelectronic circuits. ${ }^{1,2}$ On the other hand, nanowires are also widely used as chemical (reactive) or physical (nonreactive) templates for nanotubes and core-shell nanowires. ${ }^{3-5} \mathrm{The} \mathrm{ZnO}$ nanostructure is one of most studied systems, but the main attention is put to their structural, optical, and optoelectronic properties. $\mathrm{ZnO}$ is also a reactive material. A number of spineltype ternary compound nanostructures, for example, $\mathrm{ZnAl}_{2} \mathrm{O}_{4},{ }^{6,7}$ $\mathrm{Zn}_{2} \mathrm{SiO}_{4},{ }^{8} \mathrm{Zn}_{2} \mathrm{TiO}_{4},{ }^{9} \mathrm{Zn}_{2} \mathrm{SnO}_{4},{ }^{10} \mathrm{ZnGa}_{2} \mathrm{O}_{4},{ }^{11} \mathrm{ZnFe}_{2} \mathrm{O}_{4},{ }^{12} \mathrm{ZnSb}_{2} \mathrm{O}_{4},{ }^{13}$ have been synthesized either through solid-state reactions of the $\mathrm{ZnO}$ nanowire precursor with other corresponding oxides or in situ alloying.

Spinel oxides have potential applications in sorbents, battery materials, catalysts, humidity sensors, phosphors, and magnetic data storage. Some recent reports ${ }^{14}$ on 1D spinel nanomaterials indicate an increasing attention to the nanoscale fabrication and characterization of spinel materials.

Solid-state reactions of type $\mathrm{AO}+\mathrm{B}_{2} \mathrm{O}_{3} \rightarrow \mathrm{AB}_{2} \mathrm{O}_{4}$ are a common way for the fabrication of spinel oxides. Traditional studies on spinel-formation reactions are usually conducted at planar interfaces or in form of powder mixture by bringing two solid binary oxides, or a solid oxide and a vapor or liquid phase, into contact at high temperatures $\left(>1000{ }^{\circ} \mathrm{C}\right) .{ }^{15}$ The growth process of classical spinel oxides (e.g., $\mathrm{ZnFe}_{2} \mathrm{O}_{4}$ and $\mathrm{MgAl}_{2} \mathrm{O}_{4}$ ) involves Wagner's cation counterdiffusion mechanism, namely, cations migrating through the reaction interface in opposite directions and the oxygen sublattice remaining essentially fixed. ${ }^{16,17}$ The reaction of $\mathrm{ZnO}$ (wurzite structure, $a=3.250$ $\AA$, $c=5.207 \AA$ ) with $\mathrm{Al}_{2} \mathrm{O}_{3}$ into $\mathrm{ZnAl}_{2} \mathrm{O}_{4}$ spinel (cubic structure, $a=8.088 \AA$ ) is special: the growth mechanism involves the diffusion of both $\mathrm{Zn}$ and $\mathrm{O}$ and an effective

\footnotetext{
* Corresponding author. E-mail: hfan05@esc.cam.ac.uk.

Max Plank Institute of Microstructure Physics.

$\doteqdot$ University of Cambridge.

\# Albert-Ludwigs-University Freiburg.
}

unilateral transfer of $\mathrm{ZnO}$ into the spinel (see Figure $\mathrm{S} 1$ in Supporting Information). This was first pointed out by Bengtson and Jagitsch, ${ }^{18}$ and later readdressed by Navias, ${ }^{19}$ Branson, ${ }^{20}$ and Keller et al. ${ }^{21}$ This means that an inert marker plane placed at the initial interface will be found at the $\mathrm{ZnO}$ /spinel interface for the $\mathrm{ZnO}-\mathrm{Al}_{2} \mathrm{O}_{3}$ reaction, whereas in the case of the $\mathrm{MgO}-$ $\mathrm{Al}_{2} \mathrm{O}_{3}$ reaction, the marker plane is within the spinel layer. In our recent experiment of solid-solid interface reactions of core-shell nanowires, hollow spinel nanotubes were developed directly from $\mathrm{ZnO}-\mathrm{Al}_{2} \mathrm{O}_{3}$, whereas spinel shells were based on $\mathrm{MgO}-\mathrm{Al}_{2} \mathrm{O}_{3} .{ }^{22}$ This is consistent with the diffusion mechanism and a consequence of the spatial confinement given by the cylindrical symmetry of the reaction.

Depending on whether it is a solid-solid or solid-vapor reaction, the $\mathrm{ZnO}$-based spinel nanostructures mentioned above ${ }^{6-13}$ show different morphologies. For the particular interesting $\mathrm{ZnO}-\mathrm{Al}_{2} \mathrm{O}_{3}$ system, no report has been made so far for the reactions of solid $\mathrm{ZnO}$ with alumina vapor. In this study, $\mathrm{ZnO}$ nanowires were reacted in vacuum with alumina vapor generated by e-beam evaporation. E-beam evaporation in vacuum is a standard method used widely for solid-vapor reactions on bulk substrates, ${ }^{23,24,25}$ due to its merits of easy control of the deposition rate and the substrate temperature. Interestingly, after reaction, the $\mathrm{ZnO}$ nanowire surface becomes rugged due to decomposition, and some of the wires are coated by small spinel nanoparticles, a structure dramatically different from that after a solid-solid reaction. This provides a route toward singlecrystalline chainlike $\mathrm{ZnO}$ nanowires, which are difficult to grow by other methods. Such rough $\mathrm{ZnO}$ nanowires might be more advantageous for photocatalytic and/or gas sensing behavior because of a higher surface area compared to that of smooth wires.

\section{Experimental Section}

Vertically aligned $\mathrm{ZnO}$ nanowires on $\mathrm{GaN} / \mathrm{Si}$ substrates were synthesized inside a horizontal double-tube resistance furnace via a vapor transport and deposition method. ${ }^{26}$ The nanowire samples were then subjected to aluminum oxide vapor. The latter 


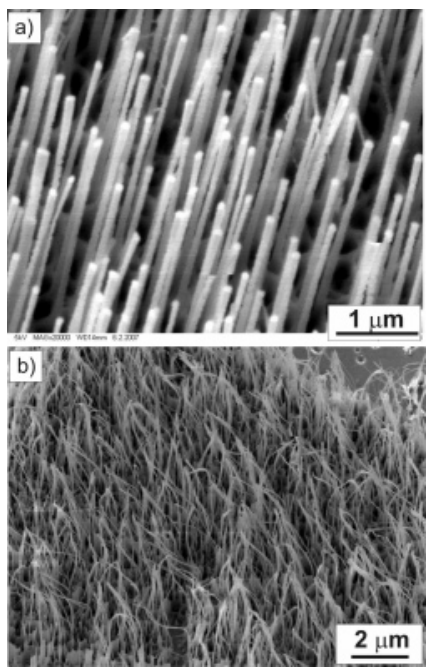

Figure 1. SEM images of the $\mathrm{ZnO}$ nanowires after reacting with $\mathrm{Al}_{x} \mathrm{O}_{y}$ vapor. Thick wires $(\sim 100 \mathrm{~nm})$ retain their vertical alignment (a) and those thin ones $(<50 \mathrm{~nm})$ become curved $(b)$.

was generated in a high-vacuum chamber by electron-beam evaporation of pressed $\mathrm{Al}_{2} \mathrm{O}_{3}$ powder tablets. The samples were hanging over the electron-beam evaporator with the nanowires facing the alumina source. The distance between evaporator and the substrates is $\approx 20 \mathrm{~cm}$, which is quite large. This minimizes the heat load on the sample and thus prevents a rise in sample temperature during deposition. The sample was heated to 800$900{ }^{\circ} \mathrm{C}$ in a tube furnace directly by thermal irradiation, before it was subjected to the vapor beam. The base pressure of the system was $<2 \times 10^{-5}$ mbar. During deposition pure oxygen was introduced to establish a pressure of $1 \times 10^{-4}$ mbar. The reaction time was in the range of 10-160 min. For comparison, one $\mathrm{ZnO}$ nanowire sample was annealed under similar conditions except that no alumina vapor was generated. After deposition, the samples were kept in the vacuum chamber and allowed to cool to room temperature.

\section{Results}

The $\mathrm{ZnO}$ nanowires stand vertically to the $\mathrm{GaN}$ surface before being subjected to the alumina vapor at 800 or $900{ }^{\circ} \mathrm{C}$. After reaction, thick nanowires retain the vertical alignment (Figure 1a) whereas those thin ones generally lose their alignment and become randomly oriented (see Figure 1b). Detailed transmission electron microscopy (TEM) investigation reveals that the initially smooth nanowires transform into a rugged morphology with necks on the surface. The degree of decomposition depends mainly on the temperature. Elongated reactions at $900{ }^{\circ} \mathrm{C}$ result in more-rugged surface than reaction at $800^{\circ} \mathrm{C}$. In addition, the nanowires after reaction at $900{ }^{\circ} \mathrm{C}$ have tiny particles attached at the necklike thinner parts of their surface. In contrast, the nanowires after the $800{ }^{\circ} \mathrm{C}$ reaction regardless of their thickness have no attachment of such nanoparticles and the whole wires become chainlike. We will examine the structures after reaction at the two temperatures separately.

Figure 2 shows the representative chainlike morphology of those thin $(<50 \mathrm{~nm})$ nanowires after being subjected to alumina vapor at $800{ }^{\circ} \mathrm{C}$. TEM analysis and the selected area electron diffraction (SEAD) pattern in Figure 3 revealed that the wires are not spinel $\mathrm{ZnAl}_{2} \mathrm{O}_{4}$, as anticipated from solid-solid reaction, ${ }^{6}$ or the reaction of vapor $\mathrm{Zn}$ with a solid alumina matrix. ${ }^{7}$ Instead, they contain mainly $\mathrm{ZnO}$ lattice without obvious growth of a spinel layer. The scanning EDX spectrum along the length of such chainlike wire (Figure 3c) shows a small amount of $\mathrm{Al}$
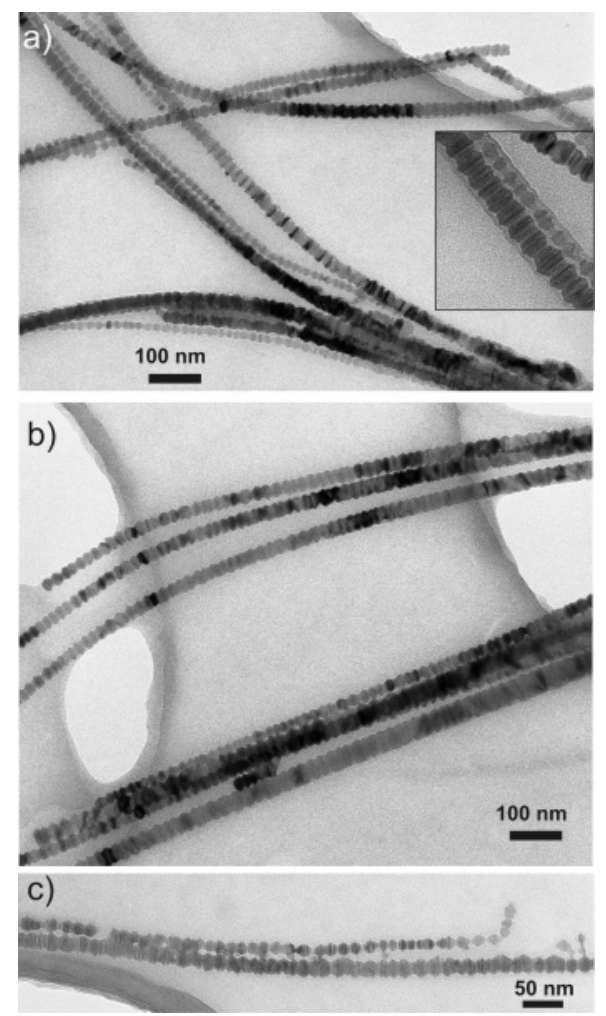

Figure 2. TEM images showing the general structure after the initially smooth $\mathrm{ZnO}$ nanowires were subjected to alumina vapor at $800{ }^{\circ} \mathrm{C}$ for $80 \mathrm{~min}$. Inset in (a) is a close-up view.

far below the stoichiometric percentrage of $\mathrm{Zn}$ spinel, which might come from a thin alumina layer on the surface. Furthermore, the reacted wires also contain a large amount of defects visible as lines across the diameter. Figure 3 a gives an example of such defects in a thin nanowire. The nature of these defects is unknown at present stage, but is most likely due to consumption of the near-surface $\mathrm{Zn}$ and $\mathrm{O}$ atoms by the reaction with alumina vapor.

Experiments were also conducted at $800{ }^{\circ} \mathrm{C}$ for various periods of time ranging from 10 to $160 \mathrm{~min}$ (see Figure S2 in Supporting Information). The nanowire surface was slightly rugged at early reactions and the surface roughness appeared unchanged for reactions until $160 \mathrm{~min}$. Again no outer layer of spinel was observed.

When the reaction temperature was raised to $900{ }^{\circ} \mathrm{C}$, spinel formed by the solid-vapor reaction on the nanowire surface. Figure $4 \mathrm{a}-\mathrm{c}$ gives an overview of the reacted wires after reaction at $900{ }^{\circ} \mathrm{C}$ for $160 \mathrm{~min}$ (some unreacted wires are also present as will be discussed later). A SEAD pattern recorded from one of the rugged wires is shown in Figure 4d. In addition to the dominating wurtzite $\mathrm{ZnO}$ spots in [1210] transmission direction, weak spots fitting to $\mathrm{ZnAl}_{2} \mathrm{O}_{4}$ spinel can be identified. The maximum depth of the necks is $\approx 42 \mathrm{~nm}$. Again, the $\mathrm{ZnO}$ crystal lattice body was preserved from the initial nanowire. Spinel nanoparticles were attached to the wire surface, mainly in the necks (Figure 5a). The measured lattice plane distance perpendicular to the wire axis corresponds to $d_{(0002)}=0.26 \mathrm{~nm}$ of wurtzite $\mathrm{ZnO}$. High-resolution TEM examination of the particles on the wire surface verified the phase of the wire body and the surface particles to be wurzite $\mathrm{ZnO}$ and cubic $\mathrm{ZnAl}_{2} \mathrm{O}_{4}$, respectively. The lattice images of two representative particles are shown in Figure 5b,c from which the lattice spacings are measured: 4.04 and $4.67 \AA$, fitting to the $d$-spacings of (002) and (111) $\mathrm{ZnAl}_{2} \mathrm{O}_{4}$ planes, respectively. ${ }^{27}$ Figure $5 \mathrm{~d}-\mathrm{f}$ displays 

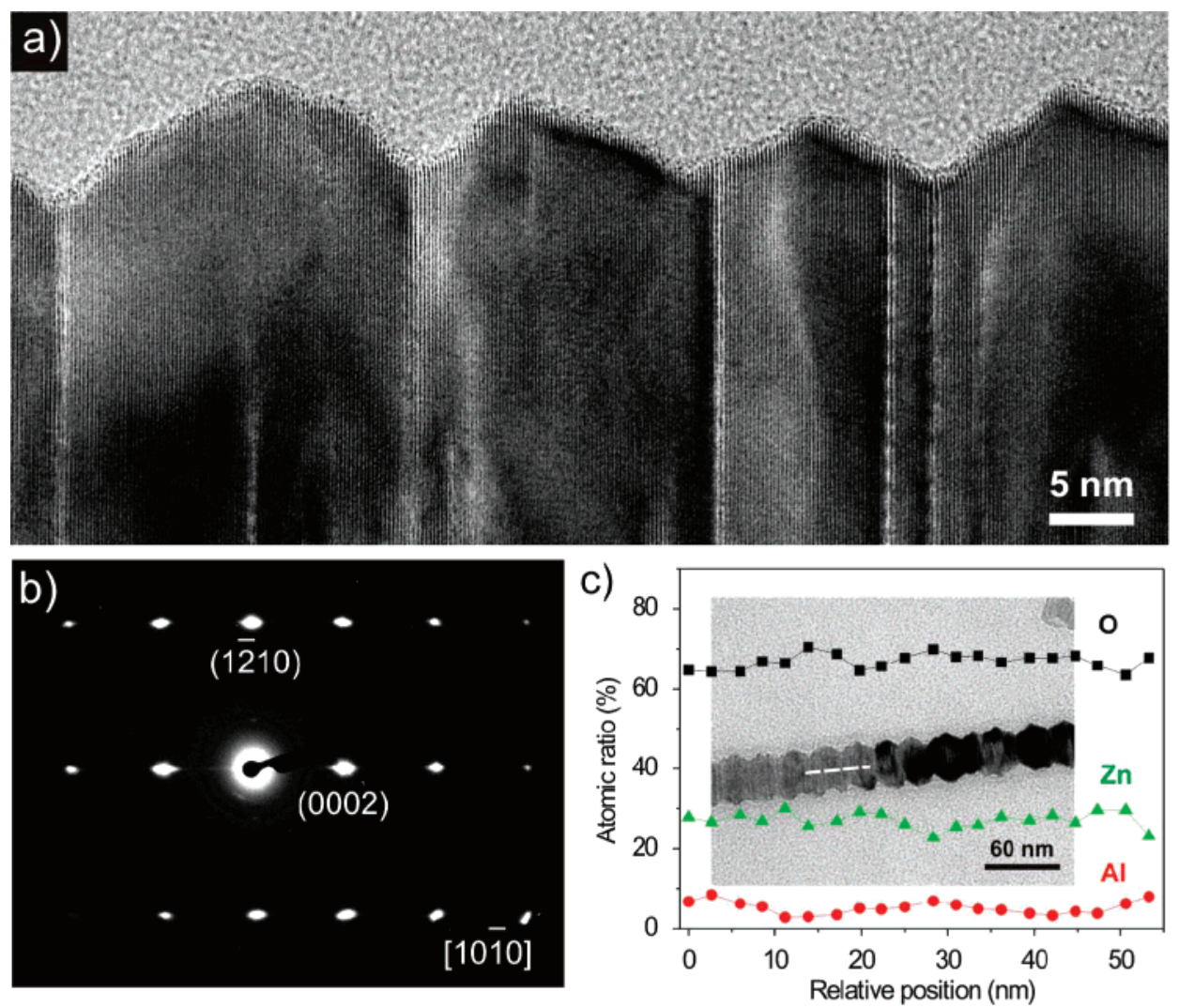

Figure 3. (a) HRTEM image of the wire surface (Figure 2) showing the necks and corresponding defect lines. (b) Electron diffraction pattern of a rugged wire verifying the absence of lattice spots from $\mathrm{Zn}$ spinel. (c) Typical spectra of atomic percentages of $\mathrm{Zn}, \mathrm{Al}$, and $\mathrm{O}$ along the dashed line in the inset image determined by EDX. The atomic ratio of oxygen is not real because of the characteristics of the instrument.

the fast Fourier transformation (FFT) patterns from two surface particles, as well as that from the wire body. Both particles are in $[-110]$ transmission, and the $\mathrm{ZnAl}_{2} \mathrm{O}_{4}$ (111), (002), and (220) spots can be easily indexed.

\section{Discussion}

The change in surface structure is not caused by thermal evaporation of the $\mathrm{ZnO}$ nanowires ${ }^{8}$ due to vacuum annealing. This is because, as shown above (Figure 4a), some smooth wires were also found in the sample subjected to vacuum reaction. These smooth wires were intact due to blockage from the alumina vapor by the sample holder during the reaction. If vacuum annealing were the cause, all the wires should be transformed. Furthermore, we annealed one $\mathrm{ZnO}$ nanowire sample under the same conditions without introducing alumina vapor. The surfaces of these nanowires remained intact (see Supporting Information, Figure S3). The equilibrium total vapor pressure of $\mathrm{ZnO}$ near $900{ }^{\circ} \mathrm{C}$ is about $4.0 \times 10^{-5} \mathrm{mbar},{ }^{28}$ which is close to the background pressure in the chamber. Therefore, evaporation of the solid $\mathrm{ZnO}$ nanowires is insignificant and cannot explain the formation of the necks.

Let us now make a comparison to other spinel 1D nanostructures. First, our previously reported $\mathrm{ZnAl}_{2} \mathrm{O}_{4}$ spinel nanotubes were obtained via a solid-solid interface reaction of $\mathrm{ZnO}-$ $\mathrm{Al}_{2} \mathrm{O}_{3}$ core-shell nanowires. ${ }^{6}$ In this case, the unilateral (outward) transport of $\mathrm{ZnO}$ into spinel resulted in hollow tubular nanowires, as a result of spatial confinement given by the cylindrical symmetry of the reaction. Moreover, control experiments were conducted in which the $\mathrm{ZnO}$ nanowires were coated with a $3 \mathrm{~nm}$ thick ALD alumina shell (to compare the results of solid-vapor and solid-solid reactions with a comparable spinel particle size). The resulting structure is internally porous composite wires with an outer smooth spinel shell of about 3 $\mathrm{nm} \cdot{ }^{29}$ Therefore, a continuous and uniform covering of alumina is the key to the formation of a smooth spinel layer.

Second, for comparison we also conducted the solid-gas reaction to $\mathrm{MgO}$ nanowires (thickness $\sim 50-100 \mathrm{~nm}$ ) under identical conditions as the ones described above. Generally, a continuous spinel-type compound layer was formed surrounding the remaining $\mathrm{MgO}$ core. An example of such structure and its corresponding composition analysis is shown in Supporting Information, Figure S4. The result is qualitatively the same as that through a solid-solid interface reaction of $\mathrm{MgO}-\mathrm{Al}_{2} \mathrm{O}_{3}$ core-shell nanowires that we reported previsouly. ${ }^{22}$ It is also in consistence with the result of solid-vapor reactions on singlecrystal $\mathrm{MgO}$ substrate ${ }^{23}$ and with solid-solid reactions between sapphire substrates and $\mathrm{MgO}$ thin films. ${ }^{30}$

Finally, in the experiment by $\mathrm{Li}$ et al. ${ }^{1 \mathrm{~b}} \mathrm{ZnO}$ nanowires were in situ reacted with $\mathrm{Ga}-\mathrm{O}$ vapor at $500{ }^{\circ} \mathrm{C}$ for $30-60 \mathrm{~min}$, forming an outer shell of $\mathrm{ZnGa}_{2} \mathrm{O}_{4}$ spinel. No hollow interior or rippled surface was observed. Similarly, our preliminary results show that an interfacial solid-solid reaction of $\mathrm{ZnO}$ core nanowire with a $20 \mathrm{~nm}$ thick $\mathrm{Fe}_{2} \mathrm{O}_{3}$ shell resulted in $\mathrm{ZnO}-$ $\mathrm{ZnFe}_{2} \mathrm{O}_{4}$ core - shell nanowires. This indicates that a diffusion process different from the $\mathrm{ZnO}-\mathrm{Al}_{2} \mathrm{O}_{3}$ system had occurred in the $\mathrm{ZnO}-\mathrm{Ga}_{2} \mathrm{O}_{3}$ and $\mathrm{ZnO}-\mathrm{Fe}_{2} \mathrm{O}_{3}$ reactions.

The above comparison leads to the suggestion that the formation of the necks might be correlated to the unilateral transfer of $\mathrm{ZnO}$ into the forming spinel particles during the surface reaction between $\mathrm{ZnO}$ and the impinged alumina. On the basis of this, a model is proposed as follows.

The alumina vapor species $\left(\mathrm{Al}_{x} \mathrm{O}_{y}\right)$ impinge the $\mathrm{ZnO}$ nanowire surface and locally react with $\mathrm{ZnO}$ due to the substrate temperature $\left(900{ }^{\circ} \mathrm{C}\right)$. Because of a slow evaporation process, 


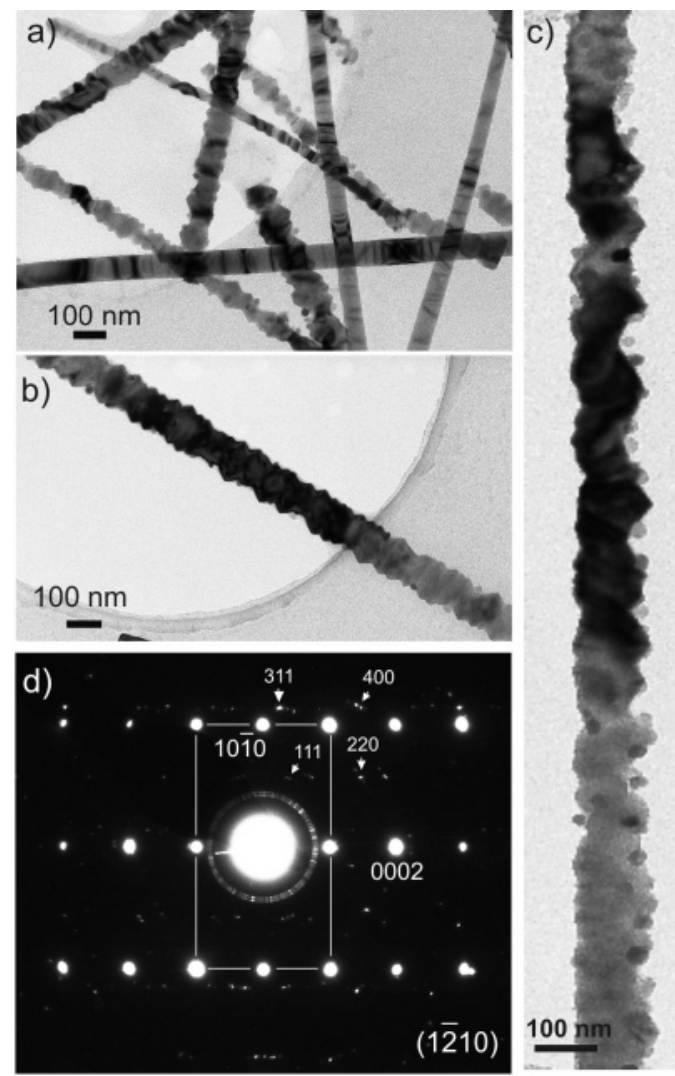

Figure 4. $(a-c)$ TEM images of general morphology of the rugged wires after reaction with $\mathrm{Al}_{x} \mathrm{O}_{y}$ vapor at $900{ }^{\circ} \mathrm{C}$ for $160 \mathrm{~min}$, showing the etching-like surface necks and attachment of particles. Note also some smooth nanowires collected from the same sample but not reacted with $\mathrm{Al}_{x} \mathrm{O}_{y}$ vapor. (d) Selected area diffraction pattern recorded from one reacted wire. The 4-digital indexes are spots from $\mathrm{ZnO}$, while 3-digital ones fit $\mathrm{ZnAl}_{2} \mathrm{O}_{4}$ spinel.

discontinuous $\mathrm{ZnAl}_{x} \mathrm{O}_{y}$ islands are formed, similar to the early stage of the solid-vapor reaction on a planar substrate. ${ }^{23}$ At the reaction interface, nanogaps analogous to the Kirkendalltype voids are generated as a result of the outward diffusion of $\mathrm{ZnO}$ into the spinel particles. ${ }^{6}$ At this stage, diffusion of $\mathrm{ZnO}$ along the surface of the necks to the reaction interface (namely, bottom of the clusters) might become the major material delivery mode, compared to the volume diffusion. ${ }^{31}$ The subsequent $\mathrm{Al}_{x} \mathrm{O}_{y}$ atoms, which do not diffuse into the volume of the nanowires, stay preferably at the surface necks or around the $\mathrm{ZnO} /$ spinel cluster interfaces, which are low-energy sites compared to the smooth surfaces. With the enlargement of the gaps by losing surface $\mathrm{ZnO}$ atoms, deeper necks as seen in Figure 3 are developed. It is noteworthy that this process is similar to the reaction of $\mathrm{TiO}_{2}$ substrate with e-beam generated $\mathrm{BaO}$ vapor, as reported by some of the authors. ${ }^{31 \mathrm{~d}}$ In the latter case, voids were observed on top of the substrate as a result of surface diffusion of $\mathrm{TiO}_{2}$ during the solid-vapor reaction, roughening the original smooth $\mathrm{TiO}_{2}$ surface.

In the experiments conducted by Wang et al. ${ }^{7 \mathrm{~b}}$ where anodic alumina membranes reacted with $\mathrm{Zn}$ vapor, a thin $(<4 \mathrm{~nm})$ layer of $\mathrm{Zn}_{4} \mathrm{Al}_{22} \mathrm{O}_{37}$ phase was detected after reaction at $650{ }^{\circ} \mathrm{C}$ for $<600 \mathrm{~min}$, whereas a $\sim 15 \mathrm{~nm}$ thick $\mathrm{ZnAl}_{2} \mathrm{O}_{4}$ spinel layer was obtained at higher temperatures for longer reaction time (800 min). The $\mathrm{Zn}_{4} \mathrm{Al}_{22} \mathrm{O}_{37}$, with an hcp crystal structure, is a transition phase of the final spinel phase. In our experiments, the small nanoparticles were determined to be $\mathrm{Zn}$ spinel based on HRTEM images and the diffraction patterns (Figure $5 b-f$ ). The possibility of the formation of a similar thin transitional
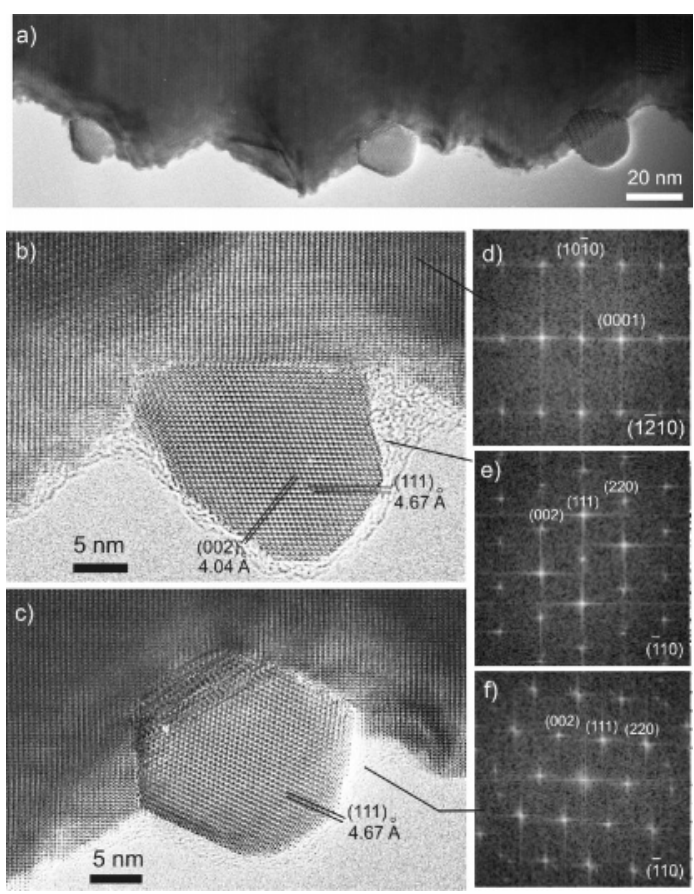

Figure 5. (a) Surface structure of the initially smooth $\mathrm{ZnO}$ nanowires after reacting with alumina vapor at $900{ }^{\circ} \mathrm{C}$ for $160 \mathrm{~min}$. (b,c) HRTEM pictures of two particles, showing the wire body is $\mathrm{ZnO}$ and particles are $\mathrm{ZnAl}_{2} \mathrm{O}_{4}$ spinel. (d-f) FFT patterns taken from the wire body particle in panels $\mathrm{b}$ and $\mathrm{c}$, respectively (The indexes sit above the spots).

layer of $\mathrm{Zn}_{4} \mathrm{Al}_{22} \mathrm{O}_{37}$ in our experiment is small because of the following reasons: first, our higher growth temperature of 900 ${ }^{\circ} \mathrm{C}$ should enhance the growth of $\mathrm{Zn}$ spinel and bypass the transition phase. Second, our growth was limited by amount of alumina, in contrast to Wang's case where the growth was limited by the volume diffusion of $\mathrm{Zn}$ into the solid alumina. Therefore, the reaction in our experiments did not favor the occurrence of the $\mathrm{Zn}$-deficient phase $(\mathrm{ZnO})_{4}-\left(\mathrm{Al}_{2} \mathrm{O}_{3}\right)_{11}$.

In the case of other systems like $\mathrm{MgO}-\mathrm{Al}_{2} \mathrm{O}_{3}$ and $\mathrm{ZnO}-$ $\mathrm{Ga}_{2} \mathrm{O}_{3}$, the cations counterdiffuse during the solid-vapor reaction so that a layer of spinel shell, or polycrystalline islands, is grown around the remaining core. No pits on the nanowires are formed. Therefore, the deposition of $\mathrm{Al}_{x} \mathrm{O}_{y}$ atoms on the surfaces of the $\mathrm{MgO}$ nanowires is relatively continuous. Volume diffusion is the sole material exchange mechanism for the reaction because a continuous solid interface is maintained. ${ }^{32}$

\section{Conclusion}

In summary, a solid-vapor reaction of $\mathrm{ZnO}$ nanowires at $900{ }^{\circ} \mathrm{C}$ in vacuum with alumina vapor does not result in the anticipated $\mathrm{ZnAl}_{2} \mathrm{O}_{4}$ spinel nanowires, but rather in rippled wires of a preserved $\mathrm{ZnO}$ phase. By comparing to the result of a similar experiment on $\mathrm{MgO}$ nanowires, as well as other spinel oxide $1 \mathrm{D}$ nanostructures like $\mathrm{ZnGa}_{2} \mathrm{O}_{4}$, the morphology change is correlated to the unilateral transport of $\mathrm{ZnO}$ into alumina during the $\mathrm{ZnAl}_{2} \mathrm{O}_{4}$-forming surface reaction and the associated development of gaps at the interface. Moreover, we propose that surface diffusion of $\mathrm{ZnO}$ is the dominating mass transport process enhancing the formation of necks and thus of the rippled morphology of the wires.

As a general conclusion, it appears that both the details of a spinel forming reaction on nanowires (used as substrate and one reactant) and the morphology of the growing spinel phase critically depend on the kind of diffusion mechanism (unilateral or counterdiffusion) and on the state of aggregation (vapor or solid) of the second reactant. 
Acknowledgment. We thank Dr. A. Dadgar for providing the GaN/Si substrates and Dr. A. Berger for performing preliminary EDX analysis of the $\mathrm{MgAl}_{2} \mathrm{O}_{4}$ sample.

Supporting Information Available: Experimental details for growth of $\mathrm{MgO}$ nanowires, schematics of the accepted diffusion mechanisms for spinel formation, SEM images of $\mathrm{ZnO}$ nanowires after reaction with alumina vapor at $800{ }^{\circ} \mathrm{C}$ for 10 , 40,80 , and $160 \mathrm{~min}$, and SEM images of the $\mathrm{ZnO}$ nanowires after being subjected to vacuum annealing. This information is available free of charge via the Internet at http://pubs.acs.org.

\section{References and Notes}

(1) Lieber, C. M.; Wang, Z. L. MRS Bulletin 2007, 32, 99.

(2) Fan, H. J.; Werner, P.; Zacharias, M. Small 2006, 2, 700.

(3) Xiong, Y.; Mayers, B. T.; Xia, Y. Chem. Commun. 2005, 5013.

(4) Goldberger, J.; Fan, R.; Yang, P. Acc. Chem. Res. 2006, 39, 239

(5) (a) Shen, G. Z.; Bando, Y.; Ye, C. H.; Yuan, X. L.; Sekiguchi, T.; Golberg, D. Angew. Chem. Int. Ed. 2006, 45, 7568. (b) Hu, J. Q.; Bando, Y.; Liu, Z. W.; Zhan, J. H.; Golberg, D. Angew. Chem. Int. Ed. 2004, 43, 63. (c) Liu, Z.; Zhang, D.; Han, S.; Li, C.; Lei, B.; Lu, W.; Fang, J.; Zhou, C. J. Am. Chem. Soc. 2005, 127, 6. (d) Han, S.; Li, C.; Liu, Z.; Lei, B.; Zhang, D.; Jin, W.; Lei, X.; Tang, T.; Zhou, C. Nano Lett. 2004, 4, 1241.

(6) Fan, H. J.; Knez, M.; Scholz, R.; Nielsch, K.; Pippel, E.; Hesse, D.; Zacharias, M.; Gösele, U. Nat. Mater. 2006, 5, 627.

(7) (a) Wang, Y.; Wu, K. J. Am. Chem. Soc. 2005, 127, 9686. (b) Wang, Y.; Liao, Q.; Lei, H.; Zhang, X. P.; Ai, X. C.; Zhang, J. P.; Wu, K. Adv. Mater. 2006, 18, 943.

(8) Zhou, J.; Liu, J.; Wang, X.; Song, J.; Tummala, R.; Xu, N. S.; Wang, Z. L. Small 2007, 3, 622.

(9) (a) Manik, S. K.; Bose, P.; Pradhan, S. K. Mater. Chem. Phys. 2003, 82, 837. (b) Yang, Y.; Sun, X. W.; Tay, B. K.; Wang, J. X.; Dong, Z. L.; Fan, H. M. Adv. Mater. 2007, 19, 1839.

(10) (a) Wang, J. X.; Xie, S. S.; Yuan, H. J.; Yan, X. Q.; Liu, D. F.; Gao, Y.; Zhou, Z. P.; Song, L.; Liu, L. F.; Zhao, X. W.; Dou, X. Y.; Zhou, W. Y.; Wang, G. Solid State Commun. 2004, 131, 435. (b) Jie, J. S.; Wang, G. Z.; Han, X. H.; Fang, J. P.; Yu, Q. X.; Liao, Y.; Xu, B.; Wang, Q. T.; Hou, J. G. J. Phys. Chem. B 2004, 108, 8249. (c) Chen, H. Y.; Wang, J. X.; Yu, H. C.; Yang, H. X.; Xie, S. S.; Li, J. Q. J. Phys. Chem. B 2005, $109,2573$.

(11) (a) Chang, K. W.; Wu, J. J. J. Phys. Chem. B 2005, 109, 13572. (b) Li, Y. J.; Lu, M. Y.; Wang, C. W.; Li, K. M.; Chen, L. J. Appl. Phys. Lett. 2006, 88, 143102.
(12) Zacharias, M.; Kim, D. S. Max Planck Institute of Microstructure Physics and Albert-Ludwigs-University Freiburg, unpublished, 2008.

(13) Zeng, D. W.; Xie, C. S.; Dong, M.; Jiang, R.; Chen, X.; Wang, A. H.; Wang, J. B.; Shi, J. Appl. Phys. A 2004, 79, 1865.

(14) (a) Wu, X. C.; Tao, Y. R.; Han, Z. J.; Zhang, B. D. J. Mater. Chem. 2003, 13, 2649. (b) Bae, S. Y.; Seo, H. W.; Na, C. W.; Park, J. H. Chem. Commun. 2004, 16, 1834. (c) Zhang, Z. T.; Rondinone, A. J.; Ma, J. X.; Shen, J.; Dai, S. Adv. Mater. 2005, 17, 1415. (d) Bae, S. Y.; Lee, J.; Jung, H.; Park, J.; Ahn, J. P. J. Am. Chem. Soc. 2005, 127, 10802. 1974.

(16) Carter, R. E. J. Am. Ceram. Soc. 1961, 44, 116

(17) Rigby, E. B.; Cutler, I. B. J. Am. Ceram. Soc. 1965, 48, 95.

(18) Bengtson, B.; Jagitsch, R. Arkiv Kemi, Mineral. Geol. 1947, 24A,

(19) Navias, L. J. Am. Ceram. Soc. 1961, 44, 434

(20) Branson, D. L. J. Am. Ceram. Soc. 1965, 48, 591.

(21) Keller, J. T.; Agrawal, D. K.; McKinstry, A. Adv. Ceram. Mater. 1988, 3, 420.

(22) Fan, H. J.; Knez, M.; Scholz, R.; Nielsch, K.; Pippel, E.; Hesse, D.; Gösele, U.; Zacharias, M. Nanotechnology 2006, 17, 5157.

(23) Sieber, H.; Hesse, D.; Pan, X.; Senz, S.; Heydenreich, J. Z. Anorg. Allg. Chem. 1996, 622, 1658.

(24) Sieber, H.; Hesse, D.; Werner, P. Philos. Mag. A 1997, 75, 889

(25) (a) Lotnyk, A.; Senz, S.; Hesse, D. Solid State Ionics 2006, 177, 429. (b) Lotnyk, A.; Senz, S.; Hesse, D. Acta Mater. 2007, 55, 2671. (c) Lotnyk, A.; Senz, S.; Hesse, D. J. Phys. Chem. C 2007, 111, 6372.

(26) (a) Fan, H. J.; Lee, W.; Scholz, R.; Dadgar, A.; Krost, A.; Nielsch, K.; Zacharias, M. Nanotechnology 2005, 16, 913. (b) Fan, H. J.; Fuhrmann, B.; Scholz, R.; Himcinschi, C.; Berger, A.; Leipner, H.; Dadgar, A.; Krost A.; Christiansen, S.; Gösele, U.; Zacharias, M. Nanotechnology 2006, 17, S231.

(27) JCPDS number: $82-1539$. The spots in the FFT patterns fit better to $\mathrm{ZnAl}_{2} \mathrm{O}_{4}$ (lattice parameter: $8.0875 \AA$ ) than to $\gamma-\mathrm{Al}_{2} \mathrm{O}_{3}$ which has a fcc structure with a lattice parameter of $7.924 \AA$.

(28) Landolt-Börnstein: Numerical Data and Functional Relationships in Science and Technology; Springer-Verlag: Berlin, 1982; Vol. 17, p 358.

(29) Yang, Y. Max Plank Institute of Microstructure Physics. Private communication. See also Yang, Y., et al. J. Phys. Chem. C 2008, 112, 4068.

(30) Hesse, D.; Senz, S.; Scholz, R.; Werner, P.; Heydenreich, J. Interface Sci. 1994, 2, 221.

(31) (a) Burton, W. K.; Cabrera, N.; Frank, F. C. Philos. Trans. R. Soc London, Ser. A 1951, 243, 299. (b) Louchev, O. A. Appl. Phys. Lett. 1997 71, 3522.. (c) Fan, H. J.; Knez, M.; Scholz, R.; Hesse, D.; Nielsch, K.; Zacharias, M.; Gösele, U. Nano Lett.. 2007, 7, 993. (d) Lotnyk, A.; Senz, S.; Hesse, D. Microsc. Microanal. 2007, 13, 380.

(32) Gorla, C. R.; Mayo, W. E.; Liang, S.; Lu, Y. J. Appl. Phys. 2000, 87,3736 . 